The variation of the activity coefficient of $\mathrm{AgNO}_{3}$ solutions at $25^{\circ}$ was taken from the data of Robinson and Tait ${ }^{7}$ while the data of Harned ${ }^{8}$ was used to evaluate $\phi(\kappa a)$ for various values of $c$.

The lower curve of Fig. 2 is that of the equation as given by Adamson, ${ }^{1}$ viz.,

$$
\bar{D}_{+}\left(\mathrm{cm}^{2} / \mathrm{sec} .\right)=R T 1.074 \times 10^{-17} \lambda_{+}\left(1+\frac{c \partial \ln \gamma_{+}}{\partial c}\right),
$$

where

$$
\lambda_{+}=\lambda_{+}{ }^{0}-\left(0.221 \lambda_{+}{ }^{0}+29.9\right)(c)^{t} .
$$

The upper curve is that of the equation

$$
\bar{D}_{+}=\bar{D}_{+} 0\left(1+\frac{c \partial \ln \gamma_{+}}{\partial c}\right)
$$

where

$$
\bar{D}_{+}^{0}=R T 1.074 \times 10^{-17} \lambda_{+}{ }^{0} \text {. }
$$

In Eq. (2) $\lambda_{+}$varies with concentration while in Eq. (3) it is assumed that the thermodynamic factor adequately describes all concentration effects. Since the ionic activity coefficient cannot be measured directly the activity coefficient of $\mathrm{AgNO}_{3}$ determined by Robinson and Tait $^{7}$ was used. The general applicability of Eq. (3) to the self-diffusion of ions is being investigated.

It is evident from the figures that at low concentrations $\mathrm{Ag}^{+}$ does not behave in the same way as $\mathrm{Na}^{+}$. In the case of silver, theory and experiment agree reasonably well at infinite dilution and Eq. (3) fits the self-diffusion data satisfactorily in this concentration range.

The data of these figures are in a sense "preliminary." It is intended to repeat the tracer experiments with $\mathrm{Ag}^{110}$ of a higher specific activity and with a counter of more favorable geometry, viz., a dipping counter. Two of the points in Fig. 2 were obtained with cells in which the contents were stirred by intermittent rotation of the diaphragm (half-minute on-half-minute off). It will be observed that these points are not out of line with the results of the unstirred runs. More stirred self-diffusion runs at low concentration are planned.

A studentship, a bursary, and a grant for apparatus from the National Research Council of Canada are gratefully acknowledged.

1. A. W. Adamson, J. Chem. Phys, 15, 762 (1947).

$3 \mathrm{~K}$. J. Mysels and J. W. McBain, J. Coll. Sci. 3, 45 (1948).

5 A. R. Gordon, J. Chem. Phys. 5, 522 (1937).

H. S. Harned and A. L. Levy, J. Am. Chem. Soc. 71, 2781 (1949).

R. S. Harned, Chem. Rev. 40, 461 (1947).
H. Ho

\section{The Structure of Polymer-Plasticizer Gels As Shown by the Electron Microscope}

W. R. RIChaRD AND P. A. S. SMIth

University of Michigan, Ann Arbor, Michigan

December 16, 1949

W

$\mathrm{E}$ wish to report the use of high density organo-mercury compounds as plasticizing agents for high polymers in the study of the structure of gel systems. The opacity to electrons imparted to the plasticizers by their high mercury content makes possible the use of the electron microscope to examine visually the scale of dispersion of the components of a polymer-plasticizer gel.

Compatible organo-mercury compounds have been obtained by the addition of mercuric acetate to various unsaturated esters, such as acrylates, methacrylates, and allyl esters. The data described in this preliminary communication were obtained using methyl $\alpha$-acetoxymercuri- $\beta$-methoxypropionate $(A)$, and methyl $\alpha$-acetoxymercuri- $\beta$-methoxyisobutyrate $(B)$. Compound $(A)$ is a viscous oil, $\rho=2.29$ at $25^{\circ} \mathrm{C}$, which could be distilled at $165^{\circ} / 0.5$ $\mathrm{mm}$ with partial decomposition; compound $(B)$ is a colorless, crystalline solid; m.p. $71.5-72.5^{\circ} ; \rho=2.2$ at $25^{\circ}$ (supercooled liquid).

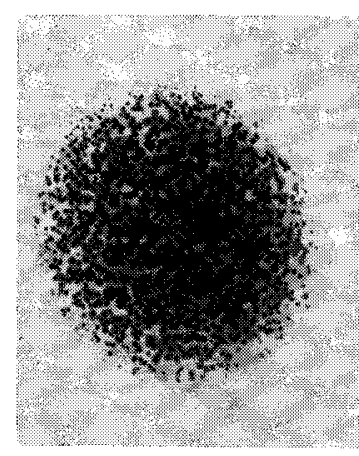

A

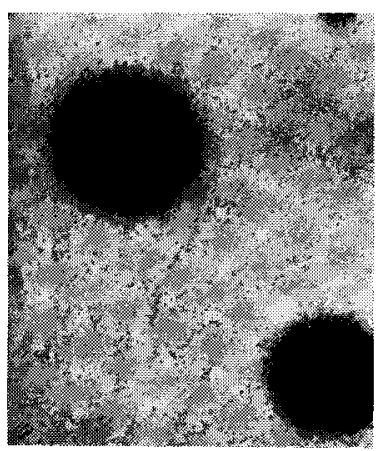

FIG. 1. Electron micrographs $\times 10,000$ of polyvinyl butyral plasticized with compounds $(A)$ and $(B)$ at volume fraction of plasticizer $\phi_{1}=0.45$.

Micrographs of polyvinyl butyral films plasticized with compounds $(A)$ and $(B)$ at volume fraction $\phi_{1}=0.45$ are shown in Fig. 1. Ovals, made up of a cluster of discrete small spheres of diameters between approximately $1300 \mathrm{~A}$ and $180 \mathrm{~A}$ as shown in Fig. 1A, appear at $\phi_{1}=0.27$ and become larger in size and number with increasing concentration of compound $(A)$. Films plasticized with $(B)$ at $\phi_{1}=0.33$ and above have small spheres of diameters between approximately $160 \mathrm{~A}$ and $115 \mathrm{~A}$ distributed at random, together with a few large dense ovals at $\phi_{1}=0.45$, as shown in Fig. 1B. Micrographs of gels at $\phi_{1}=0.2,0.12$, and 0.032 appear the same as unplasticized film showing no structure.

These pictures appear to indicate submicroscopic phase-separation commencing at plasticizer-polymer ratios above a reproducible threshold value. In order to correlate this observation with independent data, measurements of the stiffness of polyvinyl butyral plasticized with both compound $(A)$ and compound $(B)$ were made and plotted on a logarithmic scale against temperature.1,2 The temperature of maximum slope $(T \mathrm{~m})$ in the series of curves obtained is plotted against volume-fraction of plasticizer $\left(\phi_{1}\right)$ in Fig. $2^{3}$.

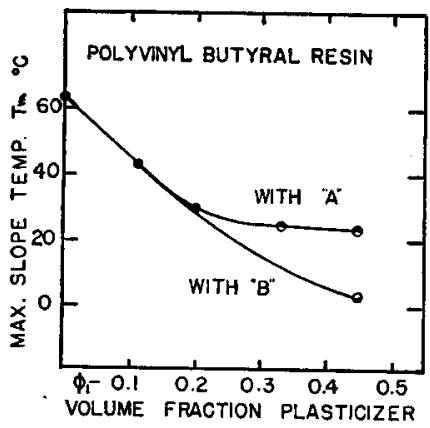

FIG. 2. Temperature of maximum slope, $(T \mathrm{~m})$, of log stiffness-temperature curves of polyvinyl butyral plasticized with compounds $(A)$ and $(B)$, plotted against volume fraction of plasticizer $\left(\phi_{1}\right)$.

The threshold of incompatibility occurs in the region of departure of the curves from a straight line as judged by the apparent phase separation shown by the electron micrographs. In addition bulk exudation was observed to occur after 1 week in the samples plasticized with compound $(A)$ at $\phi_{1}=0.33$ or higher (Fig. 2, curve $A$ ).

The use of high density organo-mercury plasticizers also allows a choice to be made of the correct parameter, weight-fraction or volume-fraction, for correlating the behavior of plasticizers in high polymer gels. The initial slopes of the curves in Fig. 2 correspond closely to that given by dibutyl phthalate in polyvinyl butyral.* However, when the same data are plotted against weight fraction the slope of the curves obtained with the high density 
mercurated plasticizers differ considerably from those obtained with plasticizers with densities near unity, such as dibutyl phthalate.

The authors wish to express their appreciation to N. N. T. Samaras, H. W. Mohrman, and C. K. Bump of Monsanto Chemical Company for resin and the use of the laboratory in determining stiffness curves, and to R. C. Williams and R. M. Fisher of the University of Michigan for aid in the techniques used in electron microscopy.

1 R. F. Clash, Jr. and R. M. Berg. Modern Plastics 21, 119 (1944).

2 G. J. Dienes and F. D. Dexter, Ind. Eng. Chem. 40, 2319 (1948).

$3 \mathrm{~L}$. Nielsen and R. Levreault, Nature 164. 317 (1949).

* Obtained by $\mathrm{E}$. McIntyre and shown by $\mathrm{R}$. Buchdahl at the High Polymer Forum of the American Chemical Society Meeting (September 19 1949).

\section{Parabolic Oxidation Rates of Metals}

WALter J. MOORE

Department of Chemistry, The Catholic University of America. Washington, D. C

December 2, 1949

$\mathrm{T}$ HE rate of growth of the thickness, $y$, of an adherent oxide film on a metal often follows the "parabolic law," $d y / d t=K / y$. The growth of the film proceeds by a diffusion of reactants through the oxide barrier. In most cases, it appears likely that the metal ions diffuse outward to the oxide-oxygen interface. Electrons also move outward to combine with adsorbed oxygen atoms, forming oxide ions. Thus successive layers of metal oxide are bult up. Owing to the formation of new oxide ions at the oxide-oxygen interface, there is a continuous solution of vacancies in the layer of oxide being formed. The resultant departure from stoichiometric composition makes the oxide a p-type semiconductor and also provides a mechanism for cation diffusion.

On the basis of this picture Mott and Gurney ${ }^{1}$ derived the expression $K=2 D_{1}\left(f_{1}-f_{2}\right)$. Here $D_{2}$ is the cation diffusion coefficient; $f_{1}$ and $f_{2}$ are the fractions of defects at the phase interfaces. Gulbransen ${ }^{2}$ combined this equation with the Eyring ${ }^{3}$ equation for $D_{2}$ to obtain $K=2 \lambda^{2}(k T / h) \exp \left(\Delta S^{\ddagger} / R\right) \exp \left(-\Delta H^{\ddagger} / R T\right)$. The closest cation to cation distance in the oxide is usually taken for $\lambda$. The derivation of the Gulbransen equation assumes that either $f_{1}$ or $f_{2}$ is negligible compared with the other.

The $\Delta S^{\ddagger}$ and $\Delta B^{\ddagger}$ are composite quantities that include the entropy or enthalpy of formation of the vacancies (or other defects) and the entropy and enthalpy of activation for diffusion. In Table $I$ are collected the available data on the parabolic rate constants for metal oxidation, in terms of the parameters of the transition state theory. Except for beryllium, there is relatively little variation in the $\Delta F^{\ddagger}$ values, so that reactions with high $\Delta H^{\ddagger}$ also have high $\Delta S^{\ddagger}$.

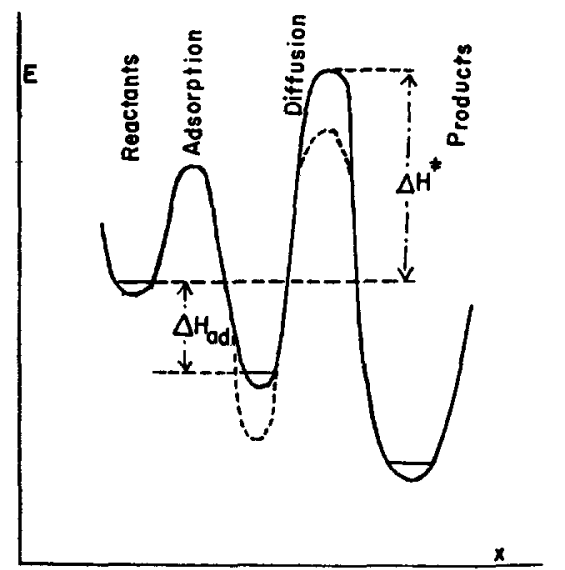

FIG. 1. Potential energy profile for oxide film formation.
TABLE I. Constants of the transition state theory for oxidation of metals.

\begin{tabular}{|c|c|c|c|c|c|c|}
\hline & Ref. & Oxide & $\lambda-\mathbf{A}$ & $\underset{\text { kcal. }}{\Delta H^{\ddagger}}$ & $\begin{array}{c}\Delta S^{\ddagger} \\
\text { cals./ } \\
\text { deg. }\end{array}$ & $\begin{array}{c}\Delta F^{\ddagger} \text { at } \\
800^{\circ} \mathbf{K} \\
\text { kcal. }\end{array}$ \\
\hline $\begin{array}{l}\text { Aluminum } \\
\text { Iron } \\
\text { Zurconum } \\
\text { Titanumum } \\
\text { Nickel } \\
\text { Copper } \\
\text { Cobalt } \\
\text { Zinc } \\
\text { Berylhum }\end{array}$ & $\begin{array}{l}(1) \\
(1) \\
(2) \\
(3) \\
(4) \\
(5) \\
(6) \\
(7) \\
(8)\end{array}$ & $\begin{array}{l}\mathrm{Al}_{2} \mathrm{O}_{3} \\
\mathrm{FeO} \\
\mathrm{ZrO}_{2} \\
\mathrm{TiO}_{2} \\
\mathrm{~N}^{\circ O} \\
\mathrm{Cu}_{2} \mathrm{O} \\
\mathrm{CoO} \\
\mathrm{ZnO} \\
\mathrm{BeO}\end{array}$ & $\begin{array}{l}2.72 \\
3.03 \\
3.42 \\
2.95 \\
2.95 \\
3.01 \\
301 \\
3.20 \\
2.69\end{array}$ & $\begin{array}{l}21.4 \\
21.2 \\
16.8 \\
24.3 \\
34.3 \\
35.5 \\
38.9 \\
33.7 \\
59.5\end{array}$ & $\begin{array}{l}-28.6 \\
-27.2 \\
-27.3 \\
-22.8 \\
-11.0 \\
-0.3 \\
+8.1 \\
-13.9 \\
-\quad 3.4\end{array}$ & $\begin{array}{l}44.3 \\
43.0 \\
38.7 \\
42.6 \\
42.3 \\
35.3 \\
32.4 \\
44.8 \\
62.2\end{array}$ \\
\hline
\end{tabular}

$1 \mathrm{E} A$ Gulbransen and W. S. Wysong, J. Phys. Colloid Chem. 51, 1087 (1947).

2 E. A. Gulbransen and K. F. Andrew, Metals Trans. 185, 515 (1949),

3 E. A. Gulbransen and K. F. Andrew, Metals Trans. 185, 741 (1949).

W. J. Moore and C. F. Downey, unpublished data.

5. B. Pilling and R. E. Bedworth, J. Inst. Metals 29,529 (1923)

- J S. Dunn and F. J. Wilkins, Revew of Oxidation and Scaling of Metals

(H. M. Stationery Office, London, 1935), p. 67.

W. J Moore and J. K. Lee, unpublished data.

8 D. Cubicciotti, personal communication.

In Fig. 1 is a schematic diagram of the potential energy barriers for vacancy formation (adsorption of oxide ions) and vacancy diffusion. The processes at the oxide-metal interface are omitted, but they may be of importance in certain instances. It will be noted that for equal diffusion barriers, the higher the heat of adsorption, the lower the effective $\Delta \boldsymbol{H}^{\ddagger}$. Since a high heat of adsorption implies an immobile adsorbed film, it may also be associated with a large negative $\Delta S$ of adsorption. This correlation may help explain the approximate constancy of $\Delta F^{\ddagger}$. In a case like that of beryllium, however, one must assume that $\Delta S^{\ddagger}$ for the diffusion process itself is exceptionally high, suggesting an extended region of disorder around the diffusing vacancy or interstitial ion.

These studies are part of a program initiated through a Frederick Gardner Cottrell grant from the Research Corporation.

1 N. F. Mott and R. W. Gurney, Electronzc Processes in Iontc Crystals (Oxford University Press, Oxford, 1940), p. 255.

2 E. A. Gulbransen, Trans. Electrochem. Soc. 83, 301 (1943). We have removed an erroneous factor of 2 from the equations of Mott and Gurney and of Gulbransen.

3 H. Eyring, J. Chem. Phys. 4, 283 (1936).

\section{On the Interpretation of the "Vapor Snake" in Freezing Cyclohexane}

\section{F. C. FRANK}

H. H. Wills Phystcal Laboratory, Royal Fort, Brtstol, England December 13, 1949

$\mathrm{P}$ HIBBS and Schiff ${ }^{1}$ describe an interesting phenomenon occurring when a sealed tube containing outgassed cyclohexane is plunged into solid $\mathrm{CO}_{2}$-acetone mixture. the development of a snake-like tubular cavity, sheathed with solid, growing at the rate of $3 \mathrm{~cm} / \mathrm{sec}$. in the interior of the liquid. They attribute this to the very high pressure vapor of cyclohexane at its melting point $\left(35 \mathrm{~mm}\right.$ at $\left.6.4^{\circ} \mathrm{C}\right)$ "along with the observed fact that crystallization tends to take place only at a liquid-vapor interface in the absence of dissolved gas." I will suggest that the latter is not a contributory cause of the phenomenon, but a parallel effect of the same cause. It is indeed theoretically conceivable that an oriented layer of molecules at the free surface of a liquid should nucleate the solid phase more readily than does the different kind of order reigning in the interior, or at the surface of contact with some solid, and experimental evidence of this would be most interesting: but it seems certain in this case that freezing occurs most readily at the free surface because the temperature is lowest there. The whole of the "vapor snake" phenomenon can be explained on the grounds that transfer of vapor into and through the cavity provides a mechanism of heat transfer additional to that of conduction through the solid sheath on the walls, which alone applies when the tube is not cooled above the liquid surface. 